\title{
1 Recognising waste use potential to achieve a circular economy
}

2 Stijn van Ewijk ${ }^{1,2}$ and Julia A. Stegemann ${ }^{1}$

$3 \quad{ }^{1}$ Center for Resource Efficiency \& the Environment (CREE), Department of Civil, Environmental \&

4

5

6

7

8

Geomatic Engineering (CEGE), University College London (UCL), London, United Kingdom

${ }^{2}$ Institute for Sustainable Resources (ISR), University College London (UCL), London, United Kingdom Corresponding author: Stijn van Ewijk (s.vanewijk@ucl.ac.uk)

\section{Abstract}

Waste management historically focused on the protection of human health and the natural environment from the impacts of littering and dispersion of pollutants. An additional and more recent concern is the resource value of waste. Our analysis shows that the regulatory concept of waste in the European Union, which comprises environmental principles, the legal definition of waste, legal requirements, and policy implementation, is not fit for addressing this concern. The legal definition of waste overlooks the context of waste, fails to consider the interests of the waste user as opposed to the waste holder, and aims to control the impacts of careless discarding rather than stimulating careful discarding. To address these challenges, we suggest a legal requirement to recognise the potential of waste to be used, operationalised by formulating a waste use potential, which expresses how and how much waste can be used as a resource, given enabling conditions. Recognition of waste use potential highlights local opportunities for reuse and recovery, reduces the likelihood of careless discarding, and reveals the interests of possible waste users to the waste holder. The waste use potential may be used in the formulation and evaluation of policies for industrial and municipal solid waste in a circular economy.

Keywords: classification; investment; behaviour change; end-of-waste; by-product; waste policy 


\section{Introduction}

Over the past few decades, waste has been regulated foremost as an inevitable and harmful residue of production and consumption. Most waste management practices are designed to protect the environment and human health from the impacts of waste through universal collection and controlled disposal. More recently, attention has shifted towards the efficient use of natural resources and a reduction of wastage (Tromans, 2001; UNEP/ISWA, 2015).

Waste represents a two-fold challenge. First, it causes impacts on the environment and human health through littering, dumping, treatment, and disposal. Second, it implies environmental losses through the wastage of scarce and valuable resources. In other words, waste is both the consequence of a problem (the result of inefficiency) as well as the cause of a problem (the source of impacts on the environment and human health).

Resource efficiency constitutes a strategy to address this challenge and is described by the European Commission as "improving economic performance while reducing pressure on natural resources through efficient use of them" (EC, 2011a). The circular economy addresses the same issue and is described by the EU Action Plan for the Circular Economy as a system "where the value of products, materials, and resources is maintained in the economy for as long as possible, and the generation of waste is minimised" (EC, 2015).

The circular economy and resource efficiency imply the minimization of material losses and the maximization of material circulation (Van Ewijk, 2018); when waste is not prevented, it should be used as a resource. However, legislation in the European Union (EU) defines anything that is discarded as waste and therefore presents no barrier to unjustified or careless discarding. This hampers waste prevention due to the administrative burden of handling regulated "waste", and because carelessly discarded items require greater separation and processing.

To deal with this issue, we analysed the challenges for waste prevention and recovery in the EU by identifying the main elements of the regulatory concept of waste, the relationship between them, and their effect on waste and resource management practices (Section 2). We specifically looked at 
how the legal definition of waste constrains behaviours and policies related to waste prevention and recovery, and have identified three critical shortcomings (Section 3).

To address these shortcomings, we suggest a legal requirement to recognise - i.e., to identify, quantify, and fulfil - the potential of waste to be used (Section 4). The requirement is complementary to the legal definition of waste, reinforces other requirements such as the waste hierarchy, and supports environmental policy formulation and evaluation. We make a general case for the recognition of waste use potential and reflect on the next steps and challenges for implementation (Section 5).

\section{Regulatory concept of waste}

\subsection{Overview of elements}

The regulatory concept of waste comprises environmental principles, the legal definition, legal requirements, and policy implementation. Figure 1 summarizes the four elements and the relationship between them. At the top are environmental principles, which inform the interpretation of the legal definition of waste (e.g., ECR (2000)), as well as the legal requirements and their implementation in policy. At the second level is the legal definition of waste, which includes the definition of waste ("waste is...") and the exceptions described by the criteria for end-of-waste status and by-product status.

The legal definition of waste is situated above the legal requirements and policy implementation because it constrains the application of legal requirements and is decisive for the implementation of policy (Bradshaw, 2018). The legal requirements directly shape the organization and regulation of waste management and inform public policies like taxes, permits, and campaigns. Most of the elements of the regulatory concept of waste were introduced or referenced by the Waste Framework Directive (WFD) (EC, 2008), the main legal framework for waste policy in the EU. The next section explains the four elements in detail. 


\subsection{Environmental principles}

The Treaty on the Functioning of the European Union (TFEU) (EC, 2012a) formulates four environmental principles that inform legal frameworks on environmental protection and sustainable development (Scotford, 2017). Three of the principles are reiterated in the WFD: the precautionary principle, the prevention principle, and the polluter-pays principle (but not the rectification-atsource principle). The principles inform the WFD and have been used to interpret the legal definition of waste (ECR, 2000).

The precautionary principle states that a lack of full scientific certainty should not be a reason to not respond to a risk of serious or irreversible environmental impacts (UN, 1992); its application requires an evaluation of "acceptable" risk (EC, 2000). The prevention principle suggests to prevent environmental impacts instead of dealing with the consequences - to rather "prevent than repair" (Van Dam et al., 1997). The polluter-pays principle requires the cost of pollution or its management to be borne by the polluter (OECD Council, 1972).

\subsection{The legal definition}

The EU Waste Framework Directive (WFD) (EC, 2008) defines waste as "any substance or object which the holder discards or intends or is required to discard".

The first exception to the legal definition consists of waste that ceases to be waste ("end-ofwaste"). The WFD states that a substance or object is no longer waste when it meets the following criteria: it has undergone a recovery operation, it is commonly used for specific purposes, and there is an existing market or demand. Besides, pollutant levels and possible adverse environmental effects must be considered. The end-of-waste criteria have been further specified for iron, steel, aluminium, and copper scrap and glass cullet, under specific regulations for these materials (EC, 2013, 2012b, 2011b).

By-product streams constitute the second exception to the legal definition. In the WFD, a substance or object qualifies as a by-product when it meets the following criteria: further use of it is 
certain, it does not need further processing other than normal industrial practice, and it is an integral part of a production process. In addition, as for any product, the use of by-products or waste that is no longer waste must be lawful (regarding existing regulations such as product standards) and should not lead to overall adverse environmental or human health impacts (EC, 2008).

The criteria for defining waste, the end-of-waste criteria, and the criteria for by-products can be sorted into four categories that relate to discarding, impact, recovery, and use. These criteria define the scope of waste legislation and provide a basic framework for its design. They are explained below, with the relation to the WFD shown in parentheses.

- Discarding. The holder discards, intends to discard, or is required to discard the substance or object (waste definition).

- Impact. The use of the substance or object does not adversely impact the environment or human health (by-products and end-of-waste).

- Recovery. The substance or object has been recovered (end-of-waste) or does not require a recovery operation (by-product).

- Use. The substance or object is commonly used (end-of-waste), there is market demand for it (end-of-waste), or further use of it is certain (by-product).

The four categories of criteria provide insight into how waste is regulated in a broad sense, but the actual waste status of a material is decided only by using the criteria in conjunction, in accordance with the rules for by-products and end-of-waste. The jurisprudence shows that the criterion of discarding supersedes the other criteria when used individually; a material cannot be classified as a non-waste merely because it can be evidenced to be recovered or used (ECR, 2000, 1997a, 1997b).

Finally, some substances or objects are effectively not a waste because they are excluded from the scope of the directive. The exclusions are gaseous effluents, unexcavated but contaminated soil, excavated but uncontaminated soil that is used on-site, radioactive waste, decommissioned 
explosives, and beneficially used natural non-hazardous agricultural or forestry material. Some other substances are excluded because they are covered by other legislation, such as waste water (EC, 2008). We do not further consider the exclusions in our analysis.

\subsection{Legal requirements}

The legal requirements relate to the waste hierarchy, permits for waste treatment, Extended Producer Responsibility (EPR), recycling and recovery targets, and waste prevention programs. The most prominent legal requirement in the WFD is the waste hierarchy, a priority order for waste management options (Van Ewijk and Stegemann, 2016). The hierarchy in the WFD states that waste prevention is most desirable (consistent with the prevention principle), followed by preparing for reuse, recycling, other recovery, and disposal. The formulation "preparing for reuse" instead of "reuse" serves the purpose of regulating "checking, cleaning or repairing, recovery operations" which enable reuse as a form of waste prevention (EC, 2008).

The various other requirements in the WFD are consistent with the waste hierarchy and intended to support the protection of the environment and human health and a move towards a "European recycling society". The requirement to have a permit applies to any establishment or undertaking carrying out waste operations. Under EPR, manufacturers bear the cost of the end-oflife waste treatment of their products and are expected to minimize these costs. Member states are obliged to meet reuse and recovery targets for various waste streams and must establish waste prevention programs.

\subsection{Policy implementation}

The first three elements of the regulatory concept of waste are the same for every EU member state. However, the transposition of the WFD into national law and the subsequent policy implementation are unique to each country: member states are allowed to decide on the details of 
including government budgets, bureaucratic capacity, political trends, lobbying, culture, and the inherited policy landscape, leads to distinct waste management arrangements.

The following categories of public policies may be implemented, in accordance with the legal requirements laid down by the WFD (OECD, 2007; UNEP, 2015).

- Information instruments: campaigns, training, education, and product labelling to inform and equip individuals and organizations; guidance documents to help businesses comply with waste regulation and legislation.

- Economic instruments: taxes and charges that reflect environmental burdens; subsidies, loans, and tax reductions for environmentally friendly technologies; tradable permit schemes; deposit-refund schemes for packaging.

- Regulatory instruments: bans or restrictions on particular uses or export of waste; environmental quality standards regarding air, water, and soil; technical standards for industrial facilities.

- Voluntary agreements: agreements or partnerships between governments, the private sector, and the tertiary sector, which may be completely voluntary or include legally binding elements.

In addition to the above, governments may choose to support innovation and technological development through a variety of measures including public funding of research, development, and demonstration (RD\&D) activities. Finally, planning policies can play an important role in shaping waste management.

\section{Shortcomings of the legal definition}

\subsection{The logic of the legal definition}

The legal definition of waste is the heart and bottleneck of the regulatory concept of waste; this section explains its logic and shortcomings. In Section 4, we will show how these shortcomings can 
be addressed by a requirement to recognise the potential of waste to be used. Whilst the suggested requirement mainly addresses the shortcomings of the legal definition, it also reinforces the other requirements, and - consistent with our description of the regulatory concept of waste -, takes form through policy implementation.

If anything, the legal definition aims to strictly control the impact of discarded materials. It includes more rather than less waste to reduce the threat of pollution (Bontoux and Leone, 1997) and to achieve high levels of protection, consistent with the precautionary and prevention principle (ECR, 2000). Conventional chemicals or hazardous substances regulations are inadequate for waste: for products with an intended use and commercial value, the price can cover the cost of regulatory compliance and their usefulness justifies some level of harm; for substances and objects that are unwanted - waste - these mechanisms are absent.

However, regulating potential resources as waste increases the regulatory burden and makes reuse and recovery less likely. Scotford (2007) describes a tension between preventing and regulating waste: material that is likely to be reused may be either prevented from being waste by classifying it as a by-product or it may be regulated as waste to avoid pollution in case it is not reused. Scotford concludes that the jurisprudence favours regulation over waste prevention, which undermines the top priority of waste prevention in the waste hierarchy.

Previous analysis highlighted flaws of the waste hierarchy (Hultman and Corvellec, 2012; Van Ewijk and Stegemann, 2016) but the lack of prevention efforts is mainly a limitation imposed by the definition of waste, which leaves the discarding of materials "unquestioned, hampering prevention efforts" (Van Ewijk and Stegemann, 2016). The next sections elaborate three interrelated concerns regarding the legal definition of waste: 1 ) the lack of context in defining waste, 2 ) the asymmetrical treatment of waste holders and users, and 3) the lack of incentives to discard carefully. Section 4 will discuss how recognising the potential of waste may at least partially address them. 
The first concern is that the legal definition overlooks context, even though it is very important in many non-legal definitions of waste. The literature shows that waste can be defined in terms of economic value (McCormick, 1986), technical necessity and efficiency (Baumgärtner and Arons, 2003), environmental hazard and pollution (Cheyne, 2002), or interpreted as a social construct (Reno, 2014). Economic, technical, environmental, and cultural factors differ locally and through time and "waste" is therefore "transient" (Thompson, 1979), a "temporary attribute" (Dijkema et al., 2000) and "not static" (Kronenberg and Winkler, 2009).

Whether a material is not a waste is equally contextual: substances or objects have a functional, physical, technological, economic, social, and legal product lifespan (RICS, 2016; Woodward, 1997). Once any of these lifespans has been exceeded, the owner may wish to discard the substance or object, upon which it is legally defined as waste. Unfortunately, the legal definition fails to highlight that, for example, clothing that is discarded for social reasons (e.g., fashion) can still be a "nonwaste" based on functional, physical, technological, economic, and legal criteria. law should require the recognition of the potential use of waste.

\subsection{Asymmetrical treatment of waste holders and users}

A second concern is the centrality of the waste holders to the legal definition. The definition considers their actions ("to discard"), intentions ("intends to discard or discards"), and possible obligations to dispose ("required to discard"). However, the definition does not mention a possible waste user; neither does it describe a category of waste that should not be discarded for the sake of 
this waste user. In fact, the WFD only defines the "waste producer", "waste holder", "dealer", and "broker" but not a potential "user" to be considered by the aforementioned parties.

Currently, the waste holder is allowed to freely discard potentially valuable materials, which leads to their regulation as waste. At the same time, the waste user has to actively prove that the waste is actually a resource, by showing that the end-of-waste criteria apply. Preventing "unjustified" discarding would require a reversal of the current system: to be allowed to discard a material, its holder would have to actively prove that the material is not potentially valuable or useful.

There is an obvious problem with a reversal of the burden of proof: faced with a barrier to discard, the waste holder may resort to fly-tipping instead. A costly or inconvenient obligation to prove that materials are waste and cannot be used would be consistent with the polluter-paysprinciple but it would also stimulate waste trafficking and illegal disposal, which is driven by the cost of waste management (Europol, 2011). A "soft approach" would be to inform and incentivize waste users to ensure they consider not discarding it; a requirement to recognise the potential of waste would serve exactly this purpose.

\subsection{Lack of incentives to discard carefully}

Finally, when discarding is inevitable, waste is ideally brought to the correct bins or collection points, but the regulatory concept of waste does little to discourage the waste holder from careless discarding or to encourage careful discarding. Careless discarding - without considering its necessity or the possibility of another user - occurs because the waste holder does not see any further use of the substance or object. Careless discarding can lead to waste becoming contaminated, damaged or incorrectly sorted, which diminishes the chances of recovery.

Careless discarding of waste is partly driven by negative perceptions of waste. Besides having no further use to its holder, waste is "out of place" (Douglas, 1966) and the holder may wish to be as far as possible from it. Waste is a social categorization that evokes a repulsion that is not necessarily explained by the inherent properties of the material (Reno, 2014); any engagement with waste 
beyond getting rid of it may be considered inappropriate and somehow degrading or embarrassing

252

253

254

255

256

257 for those involved.

Carelessness is rooted in a value judgement about waste (Wilkinson, 1999) and may therefore be avoided through a change in perceptions. Careful discarding requires awareness among waste holders of the importance of recovery and recycling of waste upon correct sorting and discarding: if waste holders saw waste as an object one merely has no use for, but which requires care to retain its value to others, they could be more likely to discard it appropriately.

Current legal requirements, including the waste hierarchy, and current policies such as separate collection, imply a potential use of a waste but do not express this directly. Most importantly, they do not communicate the potential benefits of not discarding an item that is considered unwanted by the current holder. Recognition of the potential of waste to be used, which emphasises the value of waste to the next user, could help stimulate a change in perceptions.

\section{The use potential of waste}

\subsection{Recognising the potential of waste}

The shortcomings of the legal definition of waste may be addressed by introducing a legal requirement to recognise - i.e., to identify, quantify, and fulfil - the potential of waste to be used.

The principle can be operationalised by formulating waste use potential, which expresses how and to what extent a waste might be used as a resource, given enabling conditions. Recognizing the use potential of waste responds to all challenges identified in the preceding section.

1. It emphasizes the importance of context by highlighting the possibilities for utilisation. Ideally, the waste holder is prompted to seek other options than discarding the material. The waste holder may be confronted with economic, technical, environmental, and cultural criteria that lead to a different or more nuanced evaluation of the waste status of a substance or object. 
2. It compensates for the asymmetry between the waste holder and the waste user in the legal definition. Recognition of use potential reflects the judgement of the waste user, not the waste holder. It may stop the waste holder from conducting a self-centred evaluation of the usefulness of an object or substance and helps the holder to identify a third party for whom the waste may constitute a resource.

3. It can incentivise careful discarding. Recognition of the value of waste by the waste holder avoids the negative connotation of the cultural category "waste" and supports further engagement with the fate of the material. Reframing waste as a substance or object with a potential use, irrespective of who the next user is, may stimulate more careful discarding and correct source separation.

The waste use potential reinforces and goes beyond the waste hierarchy by providing materialspecific and context-specific information and by directly challenging the discarding of materials that could be used instead. The relationship between the suggested legal requirement and the legal definition of waste is explained in more detail in the next section.

\subsection{Relation to the legal definition}

The requirement to recognise the use potential of waste adds a fifth category of potential use to the criteria for assessing waste, besides discarding, impact, recovery, and use (see Section 2.2). However, whereas the first four categories are used to legally define waste, the fifth category operates at the lower level of legal requirements, and aims to change and improve activities like discarding and recovery, rather than observing these activities only for the purpose of defining the materials involved.

The legal requirement to recognise the use potential of waste is complementary to the legal definition; it is not intended as an amendment or direct extension of the legal definition of waste because it does not define whether something is a waste or not. The criterion of potential use is different from the criterion of use because the use criteria are limited to common or certain further 
use or existent market demand. The potential use covers a wider set of possibilities that are constrained by assumed enabling conditions.

Our suggestion is distinct from a value-based definition (Wilkinson, 1999) because such a definition applies the "market demand" argument already present in the end-of-waste criteria. The application of this argument in the legal definition, as opposed to a legal requirement, risks losing regulatory control over discarded materials that are alleged to be valuable. Analysing the use potential through an assessment of the context of waste can help to identify potentially valuable wastes without losing regulatory control over discarded materials.

Recognition of the use potential of waste fulfils a role the legal definition cannot: it shows what can potentially be done and thereby stimulates a shift to the best possible waste treatment and recovery operations. Whereas the legal definition is restrictive, the recognition of potential use is enabling. Importantly, the recognition of potential can help bridge the gap between "no use of waste" and "use of non-waste" by indicating which waste has the highest potential to become a resource and should therefore be prioritized in waste management policy and investment.

\subsection{Introducing the legal requirement}

A legal requirement to recognise the potential entails the formulation of waste use potential for individual categories of waste, by expressing how and to what extent the waste might be used as a resource, given enabling conditions. Whereas waste is currently labelled most commonly by origin, type of material, or hazardousness, listing waste use potential introduces information that directly serves its management or the planning and investment for future management.

We suggest a requirement to formulate use potential broadly at the level of the EU and in more detail at the level of member states; we expect waste use potential to be most helpful when specified for the national or local context. The formulation should consider national or local factors that act as barriers and enablers for reuse and recovery, including technological development, contamination and toxicity, markets and transport distances, and social and cultural context (Van Ewijk et al., 2018). 
Once formulated, waste use potential can inform the design of products, production processes,

and policies. First, for products and production processes, decisions that yield less waste or waste with a higher use potential should be given preference. Second, in waste management, the use potential of waste should in principle be fulfilled, and any constraints preventing this should be addressed in planning and investment. Third, in policy design, whenever possible, the specific use potential of waste should be considered.

A natural home for this legal requirement would be the WFD and further implementation and enforcement could build on existing directives. For industrial waste generation and management, waste use potential could inform Best Available Techniques (BATs) in the reference documentation (BREFs) for industrial permitting under the Industrial Emissions Directive (IED) (EC, 2010). For example, the BREF for the pulp and paper industry suggests using waste as an industrial feedstock, for land spreading, or in construction materials (Suhr et al., 2015); clearer and more specific guidance could be given by formulating a waste-specific use potential.

For consumer waste, a requirement to communicate use potential could improve waste generation and management. The most significant barrier to waste prevention is a lack of understanding of "waste prevention", the associated actions, and the difference between waste reduction and recycling (Cox et al., 2010); recognition of waste use potential could remedy these issues by supplying use potential information as part of the waste collection infrastructure, on product packaging, and through general media channels.

For product design, the eco-design directive $(E C, 2009)$ provides a further avenue for requiring recognition of waste use potential, since it already lists some relevant aspects: the diversity of materials and components, ease of disassembly and access to materials, level of standardization and coding, and technical recyclability. For product designers, waste use potential expresses the likelihood of end-of-life products being used as a resource, conditional upon their properties and context, and could inform eco-design. 

currently sets targets for the recovery and recycling of several waste streams, such as a minimum collection rate of $50 \%$ of at least paper, metals, plastic, and glass. Such targets, as well as the actual achieved rates, may be compared with waste use potential under various conditions. This would make a better benchmark than the implied maximum of " $100 \%$ recycling", which is not feasible due to, among others, additions to stock and dissipative losses (Van Ewijk et al., 2017).

\section{Implementing the requirement}

\subsection{Operationalising use potential}

Formulating waste use potential requires a standardized methodology for measuring and communicating how and to what extent waste can be used as a resource. The "how" can be detailed by referring to the main categories of preparing for reuse, recycling, and recovery. Recovery may be subdivided into energy recovery (substituting fuels) and non-energy recovery (substituting other materials). These categories can be subdivided again. Energy recovery, for example, can be further specified as combustion, anaerobic digestion, pyrolysis, or gasification.

Both the "how" and the "extent" of potential use depends on the properties of the waste and the "enabling conditions", which cover available technologies, practices, and infrastructure. For example, certain materials may be recycled if separate collection infrastructure is put in place, or a specific fraction of a material may be recovered if the relevant technology is further developed and commercialized. Further specification may focus on the spatial and temporal scale of the assessment and the assumptions regarding the economic, technical, environmental, and social conditions.

Of course, the potential to use waste should only be exploited insofar this is environmentally, economically, and socially acceptable. The WFD states that departure from the waste hierarchy is acceptable based on "technical feasibility, economic viability and environmental protection" (EC, 
the likely impacts of potential uses of waste, which can be achieved by applying standardized assessment methodologies, such as life cycle assessment (LCA).

\subsection{Indicators for waste use potential}

The waste use potential should be communicated using appropriate metrics and together with the enabling conditions. There is a wealth of studies on waste-related metrics but they do not include metrics that emphasize the potential use of waste (Fischer-Kowalski et al., 2011; Moriguchi, 2007). Instead, most metrics capture the extent to which waste is generated and the fraction of waste that is already used as a resource. They do not directly indicate limitations or possibilities for the use of waste as a resource.

An exception is Park and Chertow (2014), who present an indicator emphasizing the technical possibilities for using waste as a resource. The "reuse potential indicator" shows the fraction of waste that is "resource-like" on a scale from 0 to 1 . Here, the term "reuse" is not consistent with the WFD since the analysis focuses on the US; in EU terminology, the indicator signifies the technically available options for preparing for reuse, recycling or recovery before consideration of economic and regulatory barriers.

Park and Chertow (2014) considered three cases for the use of Coal Combustion By-products (CCBs) in the United States: 1) all legally allowable uses, 2) all legally allowable uses except controversial land applications, and 3) only encapsulated use. The results ranged from a high potential of $85 \%$ in the first case to a low potential of $35 \%$ in the third case. Metrics can thus be used to indicate the use potential of waste under different economic, technical, or regulatory scenarios with distinct spatial and temporal boundaries.

A more detailed framework for classifying wastes is being developed by applying the United Nations Framework Classification for energy and mineral resources (UNFC) to "anthropogenic resources", based on socio-economic viability, field project status and viability, and the level of confidence in the potential recoverability of the quantities (UNECE, 2018). The UNFC is meant to provide transparency for investors and the application to waste still requires expansion of the 
guidance on economic, environmental, and social aspects. The waste use potential may be formulated taking guidance from this standard.

\subsection{Data requirements and limitations}

Application of waste use potential is not without challenges. Its success depends foremost on data availability regarding waste generation, waste properties, and use options. Significant data collection efforts are necessary to gather this information; the required level of detail depends on the application. Whatever the data quality, it is important to specify the assumptions and uncertainties regarding a particular expression of waste use potential, since these reveal the required conditions to enable fulfilment of the potential.

For example, Van Ewijk et al. (2018) quantified the recovery potential of paper waste in the global paper life cycle based on benchmark performance and a literature review of waste use options. The study reveals that data is not widely available and that data collection efforts are hampered by inconsistent terminology. The results suggest that most pulp and paper wastes can be fully recovered, however, this is feasible only under the conditions found in highly developed pulp and paper sectors in advanced economies such as Finland.

A more detailed and locally specified assessment of the same waste flows could inform the BAT for the pulp and paper industry in the European Union. Additional data would be needed to indicate benchmark performance in the European context, which may be gathered through, for example, case studies or industry surveys. Industry regulators are likely to have much more data than is publicly available (based on permitting, monitoring, and enforcement activities) and this could be used to quantify, for an entire industry, the use potential of waste. alternatives for disposal, such as "recovery" options that cause harm or do not actually substitute virgin materials. If the impacts are not fully known, the precautionary principle suggests to pursue only those options that pose acceptable risks. Effective application of the waste use potential 
therefore requires good knowledge of not only potential use and the enabling conditions but also the associated environmental and social impacts.

428

\section{Conclusions}

The regulatory concept of waste is suitable for protecting human health and the natural environment but does not adequately address the conservation of natural resources. We analysed shortcomings in the legal definition of waste in the EU and described how to address these. The following three conclusions can be drawn from our analysis.

1. The legal definition of waste overlooks the context of waste and fails to consider the interests of the waste user as opposed to the waste holder. It aims to control the impacts of careless discarding rather than stimulating careful discarding.

2. These issues may be resolved by recognising the potential of waste and formulating how and to what extent a waste might be used, given enabling conditions. Recognition of waste use potential does not change the legal definition of waste.

3. Identification, quantification, and fulfilment of waste use potential are critically dependent on the availability of data on waste generation and management options and evidence of the associated environmental and social impacts.

A quantified waste use potential may be used for the formulation and evaluation of industrial and municipal solid waste management policy. It may be used for target setting, permitting, and to directly inform individuals or organizations about the potential use of waste as a resource. Further research may focus on developing the concept by applying it to various wastes and exploring policy applications.

\section{Acknowledgements}

The authors express their gratitude to Julian Allwood, Aiduan Borrion, Paul Ekins, Jooyoung Park, and, especially, the anonymous reviewers for thoughtful comments on earlier versions of this 
article. The authors are grateful to Colin Rose and Kell Jones for fruitful discussions on the definition

452

453

454

455

456

457

458

459

460

461

462

463

464

465

466

467

468

469

470

471

472

473

474

475 of waste.

\section{Conflict of interest}

All authors declare no conflicts of interest.

\section{References}

Baumgärtner, S., Arons, J., 2003. Necessity and Inefficiency in the Generation of Waste. J. Ind. Ecol. 7, 113-123.

Bontoux, L., Leone, F., 1997. The legal definition of waste and its impact on waste management in Europe. Sevilla.

Bradshaw, C., 2018. Waste Law and the Value of Food. J. Environ. Law 311-331. doi:10.1093/jel/eqy009

Cheyne, I., 2002. The definition of waste in EC Law. J. Environ. Law 14.

Cox, J., Giorgi, S., Sharp, V., Strange, K., Wilson, D.C., Blakey, N., 2010. Household waste prevention - a review of evidence. Waste Manag. Res. 28, 193-219. doi:10.1177/0734242X10361506

Dijkema, G.P.., Reuter, M.., Verhoef, E.., 2000. A new paradigm for waste management. Waste Manag. 20, 633-638. doi:10.1016/S0956-053X(00)00052-0

Douglas, M., 1966. Purity and order: An Analysis of the Concepts of Pollution and Taboo. Routledge, London.

EC, 2000. COMMUNICATION FROM THE COMMISSION on the precautionary principle. Brussels.

EC, 2008. DIRECTIVE 2008/98/EC OF THE EUROPEAN PARLIAMENT AND OF THE COUNCIL of 19 November 2008 on waste and repealing certain Directives. Off. J. Eur. Union.

EC, 2009. DIRECTIVE 2009/125/EC OF THE EUROPEAN PARLIAMENT AND OF THE COUNCIL of 21 October 2009 establishing a framework for the setting of ecodesign requirements for energyrelated products. Off. J. Eur. Union 10-35.

EC, 2010. DIRECTIVE 2010/75/EU OF THE EUROPEAN PARLIAMENT AND OF THE COUNCIL of 24 
November 2010 on industrial emissions (integrated pollution prevention and control). Off. J. ....

EC, 2011a. Roadmap to a Resource Efficient Europe. COM 571 Final.

EC, 2011b. Council Regulation (EU) No 333/2011 of 31 March 2011 establishing criteria determining European Parliament and of the Council L94/2-L94/11.

EC, 2012a. Consolidated version of the Treaty on the Functioning of the European Union. Off. J. Eur. Union.

EC, 2012b. Commission Regulation (EU) No 1179/2012 of 10 December 2012 establishing criteria determining when glass cullet ceases to be waste under Directive 2008/98/EC of the European Parliament and of the Council L337/31-L337/36.

EC, 2013. Commission Regulation (EU) No 715/2013 of 25 July 2013 establishing criteria determining when copper scrap ceases to be waste under Directive 2008/98/EC of the European Parliament and of the Council L201/14-L201/20.

EC, 2015. Closing the loop - An EU action plan for the Circular Economy.

ECR, 1997a. Criminal proceedings against Euro Tombesi and Adino Tombesi (C-304/94), Roberto Santella (C-330/94), Giovanni Muzi and others (C-342/94) and Anselmo Savini (C-224/95).

ECR, 1997b. Inter-Environnement Wallonie ASBL v Région wallonne.

ECR, 2000. ARCO Chemie Nederland Ltd v Minister van Volkshuisvesting, Ruimtelijke Ordening en Milieubeheer (C-418/97) and Vereniging Dorpsbelang Hees, Stichting Werkgroep Weurt+ and Vereniging Stedelijk Leefmilieu Nijmegen v Directeur van de dienst Milieu en Water v.

Europol, 2011. Europol warns of increase in illegal waste dumping [WWW Document]. URL https://www.europol.europa.eu/newsroom/news/europol-warns-of-increase-in-illegal-wastedumping (accessed 7.18.17).

Fischer-Kowalski, M., Krausmann, F., Giljum, S., Lutter, S., Mayer, a., Bringezu, S., Moriguchi, Y., Schütz, H., Schandl, H., Weisz, H., 2011. Methodology and Indicators of Economy-wide Material Flow Accounting. J. Ind. Ecol. 15, 855-876. doi:10.1111/j.1530-9290.2011.00366.x 
Hultman, J., Corvellec, H., 2012. The European Waste Hierarchy: from the sociomateriality of waste to a politics of consumption. Environ. Planning-Part A 44, 2413-2427. doi:10.1068/a44668

Kronenberg, J., Winkler, R., 2009. Wasted waste: An evolutionary perspective on industrial byproducts. Ecol. Econ. 68, 3026-3033. doi:10.1016/j.ecolecon.2009.07.006

McCormick, K., 1986. Towards a definition of waste in economics: A neoinstitutional approach. Rev. Soc. Econ. 44, 80-92. doi:10.1080/758537483

Moriguchi, Y., 2007. Material flow indicators to measure progress toward a sound material-cycle society. J. Mater. Cycles Waste Manag. 9, 112-120. doi:10.1007/s10163-007-0182-0

Nash, H.A., 2008. The Revised Directive on Waste: Resolving Legislative Tensions in Waste Management? J. Environ. Law 21, 139-149. doi:10.1093/jel/eqp001

OECD, 2007. Instrument Mixes for Environmental Policy. doi:10.1787/9789264018419-en

OECD Council, 1972. Recommendation of the Council on Guiding Principles concerning International Economic Aspects of Environmental Policies, adopted 26 May 1972, C(72)128.

Park, J.Y., Chertow, M.R., 2014. Establishing and testing the "reuse potential" indicator for managing wastes as resources. J. Environ. Manage. 137, 45-53. doi:10.1016/j.jenvman.2013.11.053

Reno, J.O., 2014. Toward a New Theory of Waste: From 'Matter out of Place' to Signs of Life. Theory, Cult. Soc. 31, 3-27. doi:10.1177/0263276413500999

RICS, 2016. Life Cycle Costing. RICS Guid. Not.

Scotford, E., 2007. Trash or treasure: Policy tensions in EC waste regulation. J. Environ. Law 19, 367388. doi:10.1093/jel/eqm022

Scotford, E., 2017. Environmental Principles and the Evolution of Environmental Law. Bloomsbury Publishing.

Suhr, M., Klein, G., Kourti, I., Rodrigo Gonzalo, M., Giner Santonja, G., Roudier, S., Delgado Sancho, L., 2015. Best Available Techniques ( BAT ) Reference Document for the Production of Pulp, Paper and Board. doi:10.2791/370629

Thompson, M., 1979. Rubbish Theory: The Creation and Destruction of Value. University of Chicago 
Press, Chicago.

529

530

531

532

533

534

535

536

537

538

539

540

541

542

543

544

545

546

547

548

549

550

551

552

Tromans, S., 2001. EC Waste Law--A Complete Mess? J. Environ. Law 13, 133-156. doi:10.1093/jel/13.2.133

UN, 1992. The Rio declaration on environment and development (1992).

UNECE, 2018. Draft Specifications for the application of the United Nations Framework Classification for Resources to Anthropogenic Resources.

UNEP/ISWA, 2015. Global Waste Management Outlook.

UNEP, 2015. Sustainable Consumption and Production: A Handbook for Policymakers.

Van Dam, Y.K., Frouws, J., Proost, M.D.C., Struik, P.C., Van der Velde, M., Varela-Ortega, C., 1997. Additional EU policy instruments for plant protection products.

Van Ewijk, S., 2018. Resource efficiency and the circular economy Concepts, economic benefits, barriers, and policies.

Van Ewijk, S., Park, J.Y., Chertow, M.R., 2018. Quantifying the system-wide recovery potential of waste in the global paper life cycle. Resour. Conserv. Recycl. 134, 48-60. doi:https://doi.org/10.1016/j.resconrec.2018.02.026

Van Ewijk, S., Stegemann, J.A., 2016. Limitations of the waste hierarchy for achieving absolute reductions in material throughput. J. Clean. Prod. 132, 122-128. doi:10.1016/j.jclepro.2014.11.051

Van Ewijk, S., Stegemann, J.A., Ekins, P., 2017. Global Life Cycle Paper Flows, Recycling Metrics, and Material Efficiency. J. Ind. Ecol. doi:10.1111/jiec.12613

Wilkinson, D., 1999. Time to Discard the Concept of Waste. Envtl. L. Rev. 1.

Woodward, D., 1997. Life cycle costing - theory, information acquisition and application. Int. J. Proj. Manag. 15, 335-344. 


\section{Environmental principles}

Precautionary principle, prevention principle, polluter-pays principle

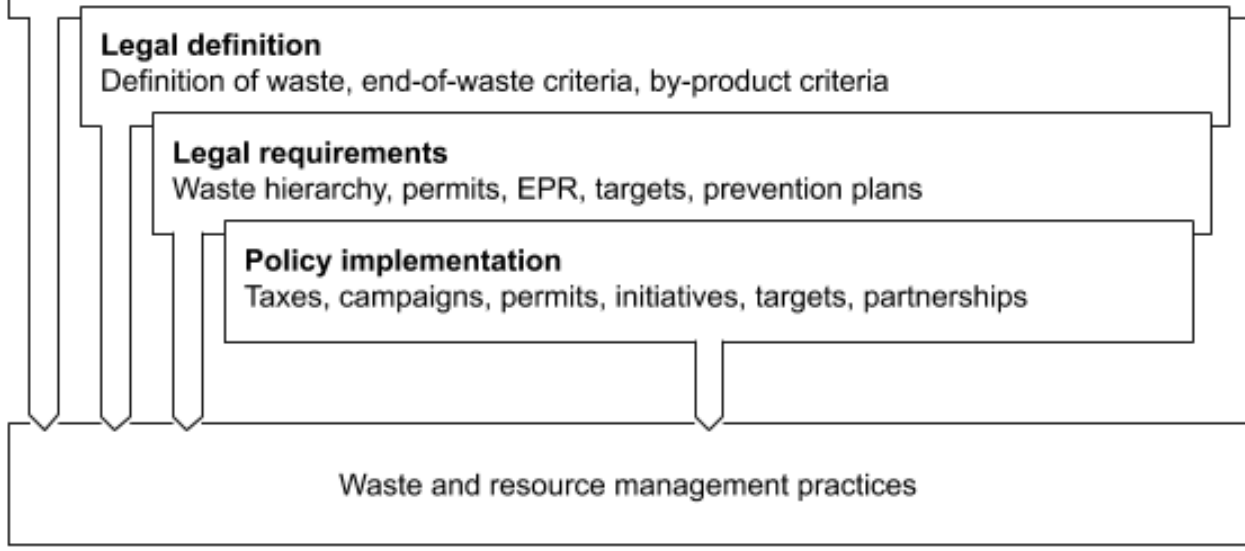

Figure 1. Four elements of the regulatory concept of waste. 